\title{
Thyroid Cancer in the Pediatric Age in Sicily: Influence of the Volcanic Environment
}

\author{
MARCO RUSSO $^{1}$, PASQUALINO MALANDRINO ${ }^{2}$, MARIACARLA MOLETI ${ }^{1}$, ANTONIO D' ANGELO ${ }^{1}$, \\ MARTINA TAVARELLI ${ }^{2}$, GIULIA SAPUPPO ${ }^{2}$, FIORENZA GIANI ${ }^{2}$, PIERINA RICHIUSA $^{3}$, \\ SEBASTIANO SQUATRITO ${ }^{2}$, RICCARDO VIGNERI ${ }^{2,4}$ and GABRIELLA PELLEGRITI ${ }^{2}$ \\ ${ }^{1}$ Department of Clinical and Experimental Medicine, University of Messina, Messina, Italy; \\ ${ }^{2}$ Endocrinology, Department of Clinical and Experimental Medicine, \\ University of Catania, Garibaldi-Nesima Medical Center, Catania, Italy; \\ ${ }^{3}$ Endocrinology, Di.Bi.M.I.S University of Palermo, Palermo, Italy; \\ ${ }^{4}$ Institute of Biostructures and Bioimaging, CNR, Catania, Italy
}

\begin{abstract}
Background/Aim: Pediatric thyroid cancer (TC) is rare but its incidence is increasing. We analyzed incidence and characteristics of pediatric TC in Sicily and comparatively evaluated data from the volcanic and nonvolcanic areas. Materials and Methods: All incident pediatric (0-19 years) TCs in Sicily between 2002-2009 were analyzed for the area of residence and compared to data for adults. Results: A total of 54 differentiated TCs (DTC) and nine medullary TCs were diagnosed in Sicily in children between 2002-2009. DTC age standardized rate for the world population (ASRw) was $0.8 / 10^{5}$ in females and $0.2 / 10^{5}$ in males, with a higher incidence in the volcanic area (ASR $w=1.4 / 10^{5}$ in females, $0.5 / 10^{5}$ in males) vs. the rest of Sicily (ASRw $=0.6 / 10^{5}$ in females, $0.1 / 10^{5}$ in males). Pediatric TCs were larger in size and more frequently with extrathyroid extension and lymph-node involvement in comparison to TCs in adults. Conclusion: In the volcanic environment of Sicily, TC incidence is markedly increased in children, suggesting a short-term effect of unidentified carcinogens of volcanic origin.
\end{abstract}

Thyroid cancer is the most common endocrine tumor and its incidence has been steadily increasing in the past two decades (1). Thyroid cancer is rare in children and

This article is freely accessible online.

Correspondence to: Riccardo Vigneri, MD, Endocrinology, Garibaldi-Nesima Medical Center, University of Catania, Via Palermo 636, 95122 Catania, Italy. Tel: +39 0957598702, Fax: +39 095472988, e-mail: vigneri@unict.it

Key Words: Pediatric thyroid cancer, thyroid cancer and volcanic environment, thyroid cancer epidemiology. adolescents: the overall age-standardized incidence rate (ASR) was 0.7 per 100,000 children in USA between 2001 and 2009 (2), increasing from 0 before age 5 years, to 0.1 at 5-9 years, 0.4 at $10-14$ years and to 1.5 at $15-19$ years (in the period 1975-2000) (3). A similar age-related trend was observed in Europe in the period 1988-97 (4).

When compared to the adult population, thyroid cancer in the pediatric age shows significant clinical, pathological and molecular differences. Thyroid nodules, for instance, are less common in children but have a higher risk of malignancy (5). Moreover, thyroid cancer often shows a more aggressive phenotype in children at diagnosis, with a greater rate of extrathyroidal extension and regional lymph-node and pulmonary metastases (6-8). This more advanced disease, however, is not associated with a higher mortality rate (less than $2 \%$ disease-specific mortality in the long term) because the response to 131-I therapy is excellent and a more favorable progression-free survival is observed in children with persistent disease $(9,10)$. These differences have induced the American Thyroid Association (ATA) to prepare specific recommendations for the management of thyroid cancer in children and adolescents up to 18 years of age, when growth and development are complete in most (11).

Similarly to what has been observed in the adult population in recent decades, an increasing incidence of thyroid cancer has also been reported in children and adolescents (1). The annual percentage change was 4.9 in the USA between 2001 and 2009 in the age range of 0-19 years (2), and a linear increase in thyroid cancer incidence has also been observed in Great Britain in all age groups, including children up to 14 years of age, with the case number doubling in a 20 -year period (12).

The reasons for the increasing incidence of thyroid cancer in the pediatric age are unclear. As for adults, better access to medical care and increased diagnostic scrutiny have most 
likely contributed to this phenomenon (13), but the increase across all tumor sizes and the small percentage of microcarcinomas in young patients suggest that a true increase is also occurring (1).

Environmental factors are suspected being primarily responsible for this rapid change of thyroid cancer occurrence (14). In younger individuals the most important and well-recognized risk factor for thyroid cancer is exposure to ionizing radiation, as demonstrated by the significant increase in papillary thyroid cancer (PTC) after the Chernobyl accident in 1986 (15), and also by the longterm trend in thyroid cancer risk among atomic bomb survivors in Japan (16) and the high prevalence of secondary thyroid cancer in children treated with external radiotherapy for other malignancies (leukemia, lymphoma, etc.) (17-20). At a young age, the thyroid is more sensitive to the damaging effect of radiation because, as in all growing tissues, the thyroid cells of children divide more rapidly, making them more sensitive to the mutagenic effects of ionizing radiation (21). The increasing use of diagnostic medical radiation, therefore, may have contributed to the increasing incidence of thyroid cancer in the young $(22,23)$. Additional environmental factors, however, cannot be excluded.

In the present study, we described the incidence and characteristics at presentation of thyroid cancer occurring in the age range of 0-19 years during the years 2002-2009 in Sicily, an island with over 5 million inhabitants, and compare the data to those found for the same age range and in the same period in the USA and to the data on the adult population in Sicily. Moreover, since a volcanic area is present in Sicily where thyroid cancer incidence is double with respect to the rest of the island (24), the epidemiological and histopathological features of pediatric thyroid cancer in these two adjacent areas of Sicily are also evaluated.

\section{Materials and Methods}

Geographical area and studied populations. Sicily is a Mediterranean island with a population of 5,037,799 inhabitants (based on the 2009 census), distributed in nine provinces (Italian Institute for Statistics, http://demo.istat.it/pop2009/index.html). Sicily is characterized by a large and easy exchange of people and goods through a dense transportation network covering the entire island. Residents have a similar genetic background and lifestyle and eating habits. Equal access to medical care is guaranteed to all resident by the National Health Service.

We previously reported that thyroid cancer incidence is markedly increased in the province of Catania, where more than $70 \%$ of the population lives in the volcanic area of Mt. Etna and uses water from the large Mt. Etna aquifer. Mt. Etna is the highest volcano in Europe and has been continuously active in recent decades (24). In the volcanic area of Mt. Etna, significantly non-anthropogenic environmental pollution is present, with increased heavy metal levels in the water and the atmosphere, leading to biocontamination of the resident population $(25,26)$.

Data on thyroid cancer in young individuals were collected in Sicily through the Sicilian Regional Register for Thyroid Cancer (SRRTC) and selectively analyzed for the young (0-19 years) vs. the adult population and for the volcanic $v s$. the non-volcanic areas. Thyroid cancer incidence and characteristics in the young in Sicily were also compared with those reported for the same age range (0-19 years) and in the same period (2002-2009) by the Surveillance Epidemiology and End Results (SEER) program in the USA (18 SEER registries) (http://seer.cancer.gov/). This register in fact, like the SRRTC, provides not only epidemiological but also clinical and pathological characteristics of incident thyroid cancer. Both these registers collect malignancy data diagnosed through histology.

Data source for the SRRTC. All thyroid cancer cases occurring in Sicily are recorded in the SRRTC, established in 2002 and based on a double independent identification system: an active search in all Sicilian pathology centers for histological diagnosis and systemic analysis of the regional database of hospital discharge records provided by the Sicilian Epidemiological Observatory and classified according to the International Classification of Diseases, Ninth Revision, Clinical Modification (https://www.cdc.gov/nchs/ icd $/$ icd $9 \mathrm{~cm} . h \mathrm{tm})$. Cancer histotype was defined according to the World Health Organization guidelines (27) considering papillary (including all variants), follicular (including all variants), anaplastic and medullary thyroid cancers. All thyroid cancers were staged according to the seventh edition of the TNM system (28). The date of surgery was considered as the date of diagnosis.

In the Sicilian cohort of pediatric thyroid cancers, no anaplastic cancer was present. Nine cases of medullary thyroid cancer were diagnosed and will be discussed separately. The comparative statistical analysis, therefore, concerns only differentiated thyroid cancers (DTC) originating from follicular thyroid cells.

Statistical analysis. Continuous variables are shown as the mean \pm standard deviation (SD), whereas the number and percentage are provided for categorical parameters. Quantitative data were compared using the $t$-test while the chi-square test was used for qualitative data. Data on numbers of newly diagnosed thyroid cancers were obtained from the SRRTC and SEER registries. Data from the SEER registry refer to the release of April 2015 (based on the November 2014 submission) and were obtained through the SEER*Stat software version 8.3.2. The incidence of thyroid cancer diagnosed in Sicily and USA during the 8-year period (2002-2009) is shown as the age-standardized rate for the world population $\left(\mathrm{ASR}_{\mathrm{w}}\right)$. Data are expressed as the number of incident cases per 100,000 residents of the studied age range with $95 \%$ confidence intervals (CI). Population data (number of inhabitants, sex and age) were obtained from the Italian Institute for Statistics. Sex- and 5-year age group-specific incidence rates were calculated. The comparisons of the incidence of thyroid cancer in different geographical areas was performed by the use of Poisson regression analysis including age and sex in the model. Statistical analyses were performed using commercially available software (Stata version 13.1; StataCorp, College Station, TX, USA) and a $p$-value of less than 0.05 was considered statistically significant. 
Table I. Differentiated thyroid cancer in pediatric age in Sicily: incidence, age at presentation, gender, histotype distribution, and tumor characteristics.

\begin{tabular}{|c|c|c|c|}
\hline & \multicolumn{3}{|c|}{ Age group } \\
\hline & 0-19 Years & 5-14 Years & 15-19 Years \\
\hline No. $(\%)$ & 54 & $11(20.4)$ & $43(79.6)$ \\
\hline \multicolumn{4}{|l|}{ ASRw $(95 \% \mathrm{CI})$} \\
\hline Females & $0.8(0.6-1.1)$ & $0.4(0.2-0.6)^{*}$ & $2.8(1.9-3.7)^{*}$ \\
\hline Males & $0.2(0.1-0.4)$ & $0.1(0.05-0.2)^{*}$ & $0.7(0.3-1.1)^{*}$ \\
\hline Female:male & 3.5 & 2.7 & 3.8 \\
\hline PTC, n $(\%)$ & $51(94.4)$ & $11(100.0)$ & $40(93.0)$ \\
\hline Mean \pm SD tumor size $(\mathrm{cm})$ & $1.8 \pm 1.4$ & $2.6 \pm 1.9$ & $1.6 \pm 1.4$ \\
\hline Microcarcinomas, n (\%) & $17(31.5)$ & $1(9.1)$ & $16(37.2)$ \\
\hline Extra-thyroidal extension, $\mathrm{n}(\%)$ & $13(24.1)$ & $4(36.4)$ & $9(20.9)$ \\
\hline Multifocality, n (\%) & $13(24.1)$ & $2(18.2)$ & $11(25.6)$ \\
\hline $\mathrm{T} 1, \mathrm{n}(\%)$ & $28(51.8)$ & $3(27.3)$ & $25(58.1)$ \\
\hline $\mathrm{T} 2, \mathrm{n}(\%)$ & $9(16.7)$ & $3(27.3)$ & $6(14.0)$ \\
\hline $\mathrm{T} 3-4, \mathrm{n}(\%)$ & $17(31.5)$ & $5(45.5)$ & $12(27.9)$ \\
\hline No, n $(\%)$ & $12(22.2)$ & $1(9.1)$ & $11(25.6)$ \\
\hline $\mathrm{N} 1, \mathrm{n}(\%)$ & $20(37.0)$ & $6(54.5)$ & $14(32.6)$ \\
\hline $\mathrm{NX}, \mathrm{n}(\%)$ & $22(40.7)$ & $4(36.4)$ & $18(41.2)$ \\
\hline Chronic lymphocytic thyroiditis, n (\%) & $23(42.6)$ & $3(27.3)$ & $20(46.5)$ \\
\hline
\end{tabular}

*Age-group specific incidence rate. ASRw: Age-standardized rate for the world population expressed as the number of incident cases per 100,000 residents; PTC: papillary thyroid cancer.

\section{Results}

Incidence, age, gender and histological distribution of DTC in pediatric age in Sicily. In the period 2002-2009, 54 DTCs were diagnosed in Sicily in patients aged 0-19 years. In this series, the mean age at diagnosis was $16.0 \pm 2.9$ years, with a progressively increasing incidence with increasing age (Table I). In the young, as in adults, DTC was more prevalent in females (42 versus 12 in males). The ASRw of pediatric DTC in Sicily was 0.5 per $10^{5}$ children/year $(95 \% \mathrm{CI}=0.4-$ $0.6), 0.8$ in females $(95 \% \mathrm{CI}=0.6-1.1)$ and 0.2 in males $(95 \%$ $\mathrm{CI}=0.1-0.4$ ), with a female/male ratio of 3.5/1.0 (Table II). The gender difference was less pronounced in children younger than 15 years (female/male $=2.7$ ) and increased in adolescents aged 15-19 years (female/male=3.8) (Table I).

Among the 54 DTCs, the papillary histotype was the most frequent $(51 / 54$ cases or $94.4 \%)$, while the follicular histotype was very rare in the pediatric age (3/54 cases or $5.6 \%$, and always occurring in patients older than 15 years). The PTC classic variant was the most frequent variant (62.7\% of all PTC cases), followed by the follicular variant $(23.5 \%)$ and the diffuse sclerosing variant $(5.9 \%)$.

Pathological characteristics of DTC at presentation in the pediatric age. The pathological characteristics of the 54 pediatric DTCs at presentation are provided in Table I, where data are also subdivided into groups younger or older than
15 years of age. Mean tumor size was greater in children aged 5-14 years than in the 15-19 year group $(p=0.055)$. There were $17(31.5 \%)$ microcarcinomas ( only one case was observed before the age of 15 years.

Extrathyroid extension and multifocal tumors were both detected in $13 / 54$ cases $(24.1 \%)$ with extrathyroid extension being more frequent in younger individuals (Table I). Large tumors (T3) were more frequent in the 5- to 14-year-old group $(45.5 \%)$ than in the 15 - to 19 -year-old patients $(27.9 \%)$. Data regarding lymph node involvement at diagnosis were available in 32 cases. The prevalence of metastasized lymph nodes was much higher in the younger group (N1 status in 6/7 cases) than in the 15-19 year old group (N1 status in 14/25 cases). The prevalence of chronic lymphocytic thyroiditis, diagnosed by histological criteria, was $42.6 \% \quad(n=23)$ in the entire series, with a higher prevalence in older children (20/43 cases) (Table I). Differences between the two groups (patients aged 5-14 vs. 15-19 years ) did not reach statistical significance because of the paucity of patients.

Comparison of DTCs incident in pediatric versus adult patients in Sicily. In the period 2002-2009, 5,328 cases of DTC were diagnosed in Sicily. Significant differences were observed between the pediatric and adult populations (Table II). The incidence was significantly higher in the adult population ( $>19$ years) with an $\mathrm{F} / \mathrm{M}$ ratio 4.5 :1.0, higher than 
Table II. Comparison of incidence, host and tumor characteristics for differentiated thyroid cancer diagnosed in the years 2002-2009 in Sicily (pediatric vs. adult age) and in the U.S. (pediatric age). Statistical significance is indicated in comparison to thyroid cancer in patients of pediatric age in Sicily.

\begin{tabular}{|c|c|c|c|c|c|}
\hline \multirow[b]{3}{*}{ No. } & \multicolumn{3}{|c|}{ Sicily (SRRTC) } & \multicolumn{2}{|c|}{ USA (SEER) } \\
\hline & $\leq 19$ Years $(2002-2009)$ & >19 Years (2002-2009) & & $\leq 19$ Years $(2002-2009)$ & \\
\hline & 54 & 5328 & $p$-Value & 1226 & $p$-Value \\
\hline \multicolumn{6}{|l|}{ ASRw $(95 \% \mathrm{CI})$} \\
\hline Females & $0.8(0.6-1.1)$ & $27.7(26.6-28.8)$ & $<0.001$ & $1.0(0.9-1.0)$ & ns \\
\hline Males & $0.2(0.1-0.4)$ & $6.3(5.7-6.8)$ & $<0.001$ & $0.2(0.2-0.2)$ & ns \\
\hline Female:male & 3.5 & 4.5 & ns & 4.4 & ns \\
\hline PTC, n (\%) & $51(94.4)$ & $4939(92.7)$ & ns & $1095(89.3)$ & ns \\
\hline Mean \pm SD age at diagnosis (years) & $16.0 \pm 2.9$ & - & & $15.9 \pm 2.9$ & $\mathrm{~ns}$ \\
\hline Mean \pm SD tumor size $(\mathrm{cm})$ & $1.8 \pm 1.4$ & $1.3 \pm 1.3$ & 0.01 & $2.5 \pm 1.7$ & 0.003 \\
\hline Microcarcinomas, n (\%) & $17(31.5)$ & $2930(55.0)$ & $<0.001$ & $190(15.5)$ & 0.004 \\
\hline Extra-thyroidal extension, $\mathrm{n}(\%)$ & $13(24.1)$ & $730(13.7)$ & 0.04 & $272(22.2)$ & $\mathrm{ns}$ \\
\hline Multifocality, n (\%) & $13(24.1)$ & $1566(29.4)$ & $\mathrm{ns}$ & $395(32.2)$ & ns \\
\hline $\mathrm{T} 1, \mathrm{n}(\%)$ & $28(51.8)$ & $3671(68.9)$ & 0.01 & $444(36.2)$ & 0.03 \\
\hline $\mathrm{T} 2, \mathrm{n}(\%)$ & $9(16.7)$ & $575(10.8)$ & $\mathrm{ns}$ & $315(25.7)$ & $\mathrm{ns}$ \\
\hline T3-T4, n (\%) & $17(31.5)$ & $890(16.7)$ & 0.009 & $369(30.1)$ & $\mathrm{ns}$ \\
\hline N0, n (\%) & $12(22.2)$ & 975 (18.3) & ns & & \\
\hline $\mathrm{N} 1, \mathrm{n}(\%)$ & $20(37.0)$ & $730(13.7)$ & $<0.001$ & & \\
\hline $\mathrm{NX}, \mathrm{n}(\%)$ & $22(40.7)$ & $3618(67.9)$ & $<0.001$ & & \\
\hline
\end{tabular}

ASRw: Age-standardized rate for the world population expressed as the number of incident cases per 100,000 residents. CI: confidence interval; PTC: papillary thyroid cancer; ns: non-significant.

in the younger age group (3.5:1.0), but not significantly. In the pediatric age, tumors were significantly larger in size at presentation, with more frequent extrathyroid extension, more frequent T3-T4 stage and more frequent lymph-node involvement (Table II), indicating the more aggressive behavior of thyroid cancer at presentation in the pediatric age.

Comparison between volcanic versus non-volcanic areas regarding pediatric DTCs in Sicily. In the period 2002-2009, 23 cases of DTC were diagnosed in the volcanic area of Sicily (province of Catania, with 1,075,657 inhabitants) and 31 in the non-volcanic area $(3,941,555$ inhabitants). As in the general population (24), DTC incidence in the volcanic area was also much higher in the pediatric population in females $(p=0.006)$ and males $(p=0.03)$ compared to the rest of Sicily, being more than 2-fold higher in respect to that in the control area. These differences were significant for both females and males (Table III). The female to male ratio was much lower in the volcanic area: $2.8 v s .4 .2: 1.0$ in the control area, but this difference did not reach statistical significance.

Small differences including earlier age, more frequent extrathyroid cancer extension, multifocality and more frequent neck lymph node involvement were observed in children resident in the volcanic area (Table III), suggesting the possibility of a more aggressive DTC phenotype in pediatric patients in the volcanic area. These DTC characteristics at presentation, however, were not statistically different between the two areas. Moreover, in children living in the volcanic area, a higher incidence of microcarcinomas [10/23 (43.5\%) vs. 7/31 (22.6\%) in the rest of Sicily] was observed, apparently in contrast with previous features of increased aggressiveness. When excluding microcarcinomas the incidence rate ratio between the volcanic and the nonvolcanic areas decreased from 2.6 to 1.9. Macrocarcinoma incidence, therefore, was nearly doubled in the volcanic area $(\mathrm{ASRw}=0.55,95 \% \mathrm{CI}=0.29-0.96$ vs. $\mathrm{ASRw}=0.28,95 \%$ $\mathrm{CI}=0.18-0.42 ; p=0.07)$.

Finally, all DTCs in the volcanic area, but not in the nonvolcanic area, had a papillary histotype (Table III), reflecting the selective increase of this histotype in DTCs occurring in residents of the volcanic area, as previously reported (24).

Comparison of pediatric DTCs in Sicily and in the USA. Comparing the 54 pediatric DTCs diagnosed in Sicily to the 1,226 that occurred in the USA in the same period, the overall incidence was similar for both females and males although the ratio was higher in the US (4.4 vs. 3.5 in Sicily).

As in Sicily, the DTC incidence and the female/male ratio also progressively increased with age in the USA (age-specific incidence rates were 0.2 and 1.7 in Sicily in the age ranges of 5-14 and 15-19 years, respectively, vs. 0.3 and 1.9 in the USA). DTC size at presentation was significantly higher in the 
Table III. Comparison between incidence, host and tumor characteristics in pediatric differentiated thyroid cancer diagnosed in Sicily in the volcanic vs. non-volcanic areas.

\begin{tabular}{lccc}
\hline & $\begin{array}{c}\text { Volcanic } \\
\text { area }\end{array}$ & $\begin{array}{c}\text { Non-volcanic } \\
\text { area }\end{array}$ & \\
\hline No. & 23 & 31 & \\
ASRw (95\% CI) & & & \\
$\quad$ Females & $1.4(0.8-2.4)$ & $0.6(0.4-0-9)$ & 0.006 \\
$\quad$ Males & $0.5(0.2-1.1)$ & $0.1(0.1-0.3)$ & 0.03 \\
Female:male & 2.8 & 4.2 & $\mathrm{~ns}$ \\
PTC (\%) & $23(100)$ & $28(90.3)$ & $\mathrm{ns}$ \\
Mean \pm SD age at diagnosis (years) & $15.7 \pm 3.4$ & $16.6 \pm 2.0$ & $\mathrm{~ns}$ \\
Mean \pm SD tumor size (cm) & $1.5 \pm 1.4$ & $2.0 \pm 1.3$ & $\mathrm{~ns}$ \\
Extra-thyroidal extension, n (\%) & $6(26.1)$ & $7(22.5)$ & $\mathrm{ns}$ \\
Multifocality, n (\%) & $6(26.1)$ & $7(22.5)$ & $\mathrm{ns}$ \\
T1, n (\%) & $12(52.2)$ & $16(51.2)$ & $\mathrm{ns}$ \\
T2, n (\%) & $4(17.4)$ & $3(9.7)$ & $\mathrm{ns}$ \\
T3-4, n (\%) & $6(26.1)$ & $11(35.5)$ & $\mathrm{ns}$ \\
N0,n (\%) & $4(17.4)$ & $8(25.8)$ & $\mathrm{ns}$ \\
N1, n (\%) & $9(39.1)$ & $11(35.5)$ & $\mathrm{ns}$ \\
NX, n (\%) & $10(43.5)$ & $12(38.7)$ & $\mathrm{ns}$ \\
\hline
\end{tabular}

ASRw: Age-standardized rate for the world population expressed as the number of incident cases per 100,000 residents; CI: confidence interval; PTC: papillary thyroid cancer; ns: non-significant.

USA because fewer microcarcinomas were diagnosed in the SEER cohort. Therefore, the prevalence of $\mathrm{T} 1$ stage was also significantly lower in the USA than in Sicily. These differences, however, are mainly due to the pediatric DTC cases observed in the volcanic area of Sicily, while the data from the Sicilian non-volcanic area are similar to the SEER data (Tables II and III). The comparison of lymph-node involvement between the SRRTC and SEER data was not possible because the NX (lymph node involvement not known) status was not reported in the SEER series.

Medullary thyroid cancer (MTC). Nine cases of MTC were diagnosed in Sicily in the period 2002-2009 in the pediatric age ( $14.3 \%$ of all pediatric thyroid cancer, ASRw $=0.09,95 \%$ $\mathrm{CI}=0.04-0.18)$. This percentage is much higher than the overall percentage of MTC in Sicily (1.9\% of all incident thyroid cancers) (24). The higher MTC percentage in the pediatric age is influenced by active screening for familial MTC. Moreover, at variance with DTC, most cases were diagnosed at a younger age (5-14 years, 6/9 cases) and without a gender difference (female/male ratio=1.3:1.0). The median size of MTC was 0.5 $\mathrm{cm}$ (range $=0.1-1.8 \mathrm{~cm})$. The great majority of cases $(8 / 9)$ were microcarcinomas (88.9\%) because of early diagnosis based on screening for mutation of rearranged during transfection $(R E T)$ gene in children at risk for MEN2 syndrome. No case presented with extrathyroidal extension but 6/9 (66.7\%) were multifocal. Two cases had regional lymph-node metastases at diagnosis.

\section{Discussion}

The epidemiological data on thyroid cancer in the pediatric age in Sicily indicate that the incidence is lower than in the adult population and progressively increases with age. In Sicily, no case occurred under the age of 5 years in the 8year period studied and the incidence increased by sevenfold in both females and males in the older group (15-19 years) relative to the younger age group (5-14 years). Most pediatric DTCs observed in Sicily, in fact, occurred in 1519-year-old adolescents (43/54 or $79.6 \%)$.

Female predominance also increased with age (Table I) reaching a value in the older age group similar to that found in adults (3.8 in the 15-19 years age group vs. 4.5 in adults). As already reported, gender is an age-specific effect modifier for thyroid cancer incidence (29), explained by the different sex hormone pattern between females and male in the prepubertal and postpubertal ages. Estrogen receptors (ER) are present in normal and neoplastic thyroid tissue and estrogen-activated ER $\alpha$ may represent a stimulatory effect for PTC growth and progression (30-32).

Comparing the 5- to 14-year-old group to the older (15-19 years) group, we observed a larger tumor size in the younger group, where only one case of microcarcinoma was observed compared to 16 in the older group. In the younger age group, more frequent extrathyroidal extension, fewer $\mathrm{T} 1$ cases and more T3 stage, as well as more frequent lymph-node metastases were observed (Table I). Similar differences were found when DTCs in the 15- to 19-year-old group were compared to DTCs occurring in adults in Sicily (Tables I and II) and confirm that thyroid cancer characteristics at presentation in children are more aggressive, with an inverse relationship with patient age. These differences in pediatric $v s$. adult features of DTC may be the consequence of differences in the genetic background, causing earlier clinical presentation because of a more aggressive malignant genotype (33), but may also be due to the endocrine and immune characteristics of the individual. For instance, in our pediatric series, the presence of chronic lymphatic thyroiditis associated with DTC was very high $(46.5 \%)$ suggesting a potential role of autoimmunity in determining DTC evolution in younger patients.

The incidence of pediatric DTCs in Sicily (ASRw $=0.8$ in females, 0.2 in males) is similar to that reported in the USA but lower than that reported in the pool of 31 AIRTUM registries in Italy (ASRw=1.4 in females, 0.5 in males) (34). These data, however, are certainly influenced by the different genetic background, environmental context and lifestyle of the examined populations. In Italy, for instance, there is a marked difference in data for Central Italy, with an ASRw of 1.2 in 0to 19-year-old residents, and Southern Italy for which the ASRw is 0.9, closer to the value observed in Sicily, as are the genetic background and lifestyle of residents of Southern Italy. 
In Sicily, pediatric DTC characteristics at presentation were similar to those observed in the USA, despite the important genetic, ethnic and lifestyle (diet) differences between the two countries. The only significant difference was the smaller tumor size due to the higher number of microcarcinomas diagnosed in Sicily. The reason for the higher incidence of microcarcinomas in Sicily and specifically in the volcanic area is unclear. In pediatric patients, at variance with adults, a palpable mass in the neck is the main route for the detection of a thyroid nodule and thyroid cancer (35). Therefore, the proportion of incidentally discovered thyroid cancer is small because thyroidectomies for benign thyroid diseases are infrequent and occult PTCs are very rare in those younger than 18 years (36). However, the increased incidence of thyroid cancer in the volcanic area is confirmed even when only macrocarcinomas are considered $(\mathrm{ASR} w=0.55$ in young residents in the volcanic area $v s . \mathrm{ASRw}=0.28$ in the rest of Sicily). Although this difference was not significant $(p=0.07)$, the difference observed in a small number of cases (overall 37 macrocarcinomas) strongly suggest a higher risk of thyroid cancer in children living in the volcanic area.

As previously reported in the general population (24), a marked difference in DTC incidence between the volcanic area and the rest of Sicily also exists in the pediatric age and is characterized by a higher prevalence of the papillary histotype, an increased relative number of male cases and by a slightly younger age at diagnosis. The other DTC characteristics at presentation and signs of aggressiveness were not statistically different between the two areas of Sicily, although some data suggest that pediatric DTC might be more aggressive in residents of the volcanic area. These data support the possibility that the negative influence of the volcanic environment observed in the adult population is already present at a young age, indicating that the volcanic pollutants with carcinogenic activity on the thyroid exhibit their effects as early as within a few years after birth.

Recent evidence has revealed the presence of multielemental pollution in the volcanic area, with water, food and the atmosphere as possible vehicles for significant biocontamination of the residents. In particular, the concentration of many metals and trace elements is increased in the urine of adults (25) and in the scalp hair of schoolchildren living in the Mt. Etna volcanic area (26). A cause-effect link between volcanic pollutants and thyroid cancer has not been demonstrated, although the strong association in different volcanic areas suggests this possibility (37-39). The mechanism is unknown but the present observation of a carcinogenic effect already present at an early age suggests that the effect of unidentified volcanic factor(s) is rapid, occurring within 5-15 years of exposure, a time interval similar to that of exposure to radiation. After radiation exposure,the excess relative risk of thyroid cancer depends on the dose and is higher in younger patients (aged 0-4 years at the time of exposure), while it is not significant when exposed individuals are older than 20 years of age $(33,40,41)$. At variance with radiation, however, exposure to putative volcanic carcinogens in the volcanic area is chronic and begins during fetal life, when mothers are contaminated. The differentiating thyroid of the fetus is particularly sensitive to mutagenic factors and this may contribute to the early occurrence of DTCs in children and adolescents resident in the volcanic area.

The lack of information on the clinical presentation and the outcome of pediatric DTC in Sicily is a major limitation of the present study, as is the lack of information on specific risk factors (family history, previous medical radiation) for most pediatric DTC cases. All these factors may influence the epidemiology of pediatric DTC and help us to understand the observed differences.

In conclusion, our investigation confirms most previous data on pediatric DTC incidence and characteristics at presentation, including a more aggressive phenotype as well as age- and gender-related differences at a young age. The novel observation of this study is that in a volcanic environment, DTC incidence is markedly increased not only in the general population but also in children. Up to now the relevance of the environment in promoting DTC in the pediatric age has been documented only for radiation. Our observation indicates that other factors, such as those present in a volcanic environment beginning in pre-natal life, may favor the early occurrence of DTC. Why some trace elements at concentrations increased in the volcanic environment, but at non-toxic levels for the general population may be carcinogenic for the thyroid is unclear. The increased incidence of other cancer types in the volcanic area (42) suggests a broader carcinogenic effect of some of the elements in the volcanic environment. The identification of these mutagenic factors and their mechanisms of action is required to obtain a better understanding of DTC biology, to re-assess the levels of chemical toxicity and develop possible intervention measures.

\section{Conflicts of Interest}

The Authors declare that no potential conflicts exist in regard to this study.

\section{Acknowledgements}

This work was supported, in part, by the Associazione Italiana per la Ricerca sul Cancro (AIRC, Milan, Italy) (grant number IG10443) to R.V.

\section{References}

1 Vergamini LB, Frazier AL, Abrantes FL, Ribeiro KB and Rodriguez-Galindo C: Increase in the incidence of differentiated thyroid carcinoma in children, adolescents, and young adults: a population-based study. J Pediatr 164: 1481-1485, 2014. 
2 Siegel DA, King J, Tai E, Buchanan N, Ajani UA and Li J: Cancer incidence rates and trends among children and adolescents in the United States, 2001-2009. Pediatrics 134: e945-955, 2014

3 Bleyer A, O'Leary M, Barr R and Ries LAG: Cancer Epidemiology in Older Adolescents and Young Adults 15 to 29 Years of Age, Including SEER Incidence and Survival: 19752000. National Cancer Institute, NIH Pub. No. 06-5767. Bethesda, MD 2009.

4 Steliarova-Foucher E, Stiller CA, Pukkala E, Lacour B, Plesko I and Parkin DM: Thyroid cancer incidence and survival among European children and adolescents (1978-1997): report from the Automated Childhood Cancer Information System project. Eur J Cancer 42: 2150-2169, 2006.

5 Gupta A, Ly S, Castroneves LA, Frates MC, Benson CB, Feldman HA, Wassner AJ, Smith JR, Marqusee E, Alexander EK, Barletta J, Doubilet PM, Peters HE, Webb S, Modi BP, Paltiel HJ, Kozakewich H, Cibas ES, Moore FD Jr., Shamberger RC, Larsen PR and Huang SA: A standardized assessment of thyroid nodules in children con- firms higher cancer prevalence than in adults. J Clin Endocrinol Metab 98: 3238-3245, 2013.

6 Welch Dinauer CA, Tuttle RM, Robie DK, McClellan DR, Svec RL, Adair C and Francis GL: Clinical features associated with metastasis and recurrence of differentiated thyroid cancer in children, adolescents and young adults. Clin Endocrinol 49: 619628,1998

7 Harness JK, Thompson NW, McLeod MK, Pasieka JL and Fukuuchi A: Differentiated thyroid carcinoma in children and adolescents. World J Surg 16: 547-553, 1992.

8 LaFranchi SH: Inaugural management guidelines for children with thyroid nodules and differentiated thyroid cancer: Children are not small adults. Thyroid 25: 713-715, 2015.

9 Handkiewicz-Junak D, Wloch J, Roskosz J, Krajewska J, Kropinska A, Pomorski L, Kukulska A, Prokurat A, Wygoda Z and Jarzab B: Total thyroidectomy and adjuvant radioiodine treatment independently decrease locoregional recurrence risk in childhood and adolescent differentiated thyroid cancer. J Nucl Med 48: 879-888, 2007.

10 Chow SM, Law SC, Mendenhall WM, Au SK, Yau S, Mang O and Lau WH: Differentiated thyroid carcinoma in childhood and adolescence-clinical course and role of radioiodine. Pediatr Blood Cancer 42: 176-183, 2004

11 Francis GL, Waguespack SG, Bauer AJ, Angelos P, Benvenga S, Cerutti JM,Dinauer CA, Hamilton J, Hay ID, Luster M, Parisi MT, Rachmiel M, Thompson GB and Yamashita S; American Thyroid Association Guidelines Task Force: Management guidelines for children with thyroid nodules and differentiated thyroid cancer. Thyroid 25: 716-759, 2015.

12 McNally RJ, Blakey K, James PW, Gomez Pozo B, Basta NO and Hale $\mathrm{J}$ : Increasing incidence of thyroid cancer in Great Britain, 1976-2005: age-period-cohort analysis. Eur J Epidemiol 27: 615-622, 2012.

13 Davies L and Welch HG: Increasing incidence of thyroid cancer in the United States, 1973-2002. JAMA 295: 2164-2167, 2006.

14 Vigneri $\mathrm{R}$, Malandrino $\mathrm{P}$ and Vigneri $\mathrm{P}$ : The changing epidemiology of thyroid cancer: Why is incidence increasing? Curr Opin Oncol 27: 1-7, 2015.

15 Kazakov VS, Demidchik EP and Astakhova LN: Thyroid cancer after Chernobyl. Nature 359: 21, 1992.
16 Furukawa K, Preston D, Funamoto S, Yonehara S, Ito M, Tokuoka S, Sugiyama H, Soda M, Ozasa K and Mabuchi K: Long-term trend of thyroid cancer risk among Japanese atomicbomb survivors: 60 years after exposure. Int J Cancer 132: 12221226,2013

17 de Vathaire F, Haddy N, Allodji RS, Hawkins M, Guibout C, ElFayech C, Teinturier C, Oberlin O, Pacquement H, Diop F, Kalhouche A, Benadjaoud M, Winter D, Jackson A, Bezin MaiQuynh G, Benabdennebi A, Llanas D, Veres C, Munzer M, Nguyen TD, Bondiau PY, Berchery D, Laprie A, Deutsch E, Lefkopoulos D, Schlumberger M, Diallo I and Rubino C: Thyroid radiation dose and other risk factors of thyroid carcinoma following childhood cancer. J Clin Endocrinol Metab 100: 4282-4290, 2015.

18 Sigurdson AJ, Ronckers CM, Mertens AC, Stovall M, Smith SA, Liu Y, Berkow RL,Hammond S, Neglia JP, Meadows AT, Sklar CA, Robison LL and Inskip PD: Primary thyroid cancer after a first tumour in childhood (the Childhood Cancer Survivor Study): a nested case-control study. Lancet 365: 2014-2023, 2005.

19 Veiga LH, Holmberg E, Anderson H, Pottern L, Sadetzki S, Adams MJ, Sakata R, Schneider AB, Inskip P, Bhatti P, Johansson R, Neta G, Shore R, de Vathaire F, Damber L, Kleinerman R, Hawkins MM, Tucker M, Lundell M and Lubin JH: Thyroid cancer after childhood exposure to external radiation: an updated pooled analysis of 12 studies. Radiat Res 185: 473-484, 2016.

20 Kovalchik SA, Ronckers CM, Veiga LH, Sigurdson AJ, Inskip PD, de Vathaire F,Sklar CA, Donaldson SS, Anderson H, Bhatti P, Hammond S, Leisenring WM, MertensAC, Smith SA, Stovall M, Tucker MA, Weathers RE, Robison LL and Pfeiffer RM: Absolute risk prediction of second primary thyroid cancer among 5-year survivors of childhood cancer. J Clin Oncol 31: 119-1127, 2013.

21 Sinnott B, Ron E and Schneider AB: Exposing the thyroid to radiation: a review of its current extent, risks, and implications. Endocr Rev 31: 756-773, 2010

22 Memon A, Godward S, Williams D, Siddique I and Al-Saleh K. Dental x-rays and the risk of thyroid cancer: a case-control study. Acta Oncol 49: 447-453, 2010.

23 Mazonakis M, Tzedakis A, Damilakis J and Gourtsoyiannis N: Thyroid dose from common head and neck CT examinations in children: Is there an excess risk for thyroid cancer induction? Eur Radiol 17: 1352-1357, 2007.

24 Pellegriti G, De Vathaire F, Scollo C, Attard M, Giordano C, Arena S, Dardanoni G, Frasca F, Malandrino P, Vermiglio F, Previtera DM, D’Azzò G, Trimarchi F and Vigneri R: Papillary thyroid cancer incidence in the volcanic area of Sicily. J Natl Cancer Inst 101: 1575-1583, 2009.

25 Malandrino P, Russo M, Ronchi A, Minoia C, Cataldo D, Regalbuto C, Giordano C, Attard M, Squatrito S, Trimarchi F and Vigneri R: Increased thyroid cancer incidence in a basaltic volcanic area is associated with non-anthropogenic pollution and biocontamination. Endocrine 53: 471-479, 2016.

26 Varrica D, Tamburo E, Dongarrà G and Sposito F: Trace elements in scalp hair of children chronically exposed to volcanic activity (Mt. Etna, Italy). Sci Total Environ 470-471: 117-126, 2014.

27 DeLellis RA: Pathology \& Genetics: Tumours of Endocrine Organs. Vol 8. IARC Press, Lyon, France, 2004. 
28 Sobin LH, Gospodarowicz MK and Wittekind C: UICC International Union Against Cancer. TNM Classification of Malignant Tumours. 7th ed. Wiley-Blackwell, Oxford, 2009.

29 Kilfoy BA, Devesa SS, Ward MH, Zhang Y, Rosenberg PS, Holford TR and Anderson WF: Gender is an age-specific effect modifier for papillary cancers of the thyroid gland. Cancer Epidemiol Biomarkers Prev 18: 1092-1100, 2009.

30 Chaudhuri PK and Prinz R: Estrogen receptor in normal and neoplastic human thyroid tissue. Am J Otolaryngol 10: 322-326, 1989.

31 Imai Y, Yamakawa M, Matsuda M and Kasajima T: Endogenous sex hormone and estrogen binding activity in thyroid cancer. Histol Histopathol 4: 39-45, 1989.

32 Huang Y, Dong W, Li J, Zhang H, Shan Z and Teng W: Differential expression patterns and clinical significance of estrogen receptor- $\alpha$ and $\beta$ in papillary thyroid carcinoma. BMC Cancer 14: 383, 2014.

33 Cordioli MI, Moraes L, Cury AN and Cerutti JM: Are we really at the dawn of understanding sporadic pediatric thyroid carcinoma? Endocr Relat Cancer 22: R311-324, 2015.

34 AIRTUM Working Group, CCM and AIEOP Working Group. Italian cancer figures, report 2012: Cancer in children and adolescents. Epidemiol Prev 37(1 Suppl 1): 1-225, 2013.

35 Cho YY, Jang HW, Joung JY, Park SM, Jeong DJ, Kim SW and Chung JH: Trends in Thyroid Cancer Incidence in Korean Children (1999-2012) Based on Palpation and Nonpalpation Detection Methods. Eur Thyroid J 4: 252-259, 2015.

36 Franssila KO and Harach HR: Occult papillary carcinoma of the thyroid in children and young adults. A systemic autopsy study in Finland. Cancer 58: 715-719, 1986.
37 Malandrino P, Scollo C, Marturano I, Russo M, Tavarelli M, Attard M, Richiusa P, Violi MA, Dardanoni G, Vigneri R and Pellegriti G: Descriptive epidemiology of human thyroid cancer: experience from a regional registry and the "volcanic factor". Front Endocrinol 4: 65, 2013.

38 Goodman MT, Yoshizawa CN and Kolonel LN: Descriptive epidemiology of thyroid cancer in Hawaii. Cancer 61: 12721281, 1988.

39 Hrafnkelsson J, Tulinius H, Jonasson JG, Olafsdottir G and Sigvaldason H: Papillary thyroid carcinoma in Iceland: a study of the occurrence in families and the coexistence of other primary tumours. Acta oncologica 28: 785-788, 1989.

40 Ron E, Lubin JH, Shore RE, Mabuchi K, Modan B, Pottern LM, Schneider AB, Tucker MA and Boice JD Jr.: Thyroid cancer after exposure to external radiation: a pooled analysis of seven studies. Radiat Res 141: 259-277, 1995.

41 Leboulleux S, Baudin E, Hartl DW, Travagli JP and Schlumberger M: Follicular-cell derived thyroid cancer in children. Eur J Cancer 40: 1655-1659, 2004.

42 Russo M, Malandrino P, Addario WP, Dardanoni G, Vigneri P, Pellegriti G, Squatrito $S$ and Vigneri R: Several site-specific cancers are increased in the volcanic area in Sicily. Anticancer Res 35: 3995-4001, 2015. 